\title{
Indigenous conflict resolution and peace-building among the Nabdam of Ghana
}

\author{
David Naya Zuure \\ Centre for African Studies, \\ University of Education, Winneba, Ghana \\ davidsonzuurich01@yahoo.com
}

\begin{abstract}
Harmonious living is an essential ingredient for the progress of every society. This requires that conflicts which are a natural part of human life are amicably resolved when they arise. Largely, people have the options of resorting to the statuary courts system or indigenous approaches which are rooted in the customs and traditions societies for the resolution of conflicts. This study examined the indigenous conflict resolution among the Nabdam of Ghana using the descriptive design within the qualitative research paradigm. It involved thirty persons from the area consisting chiefs, elders, and individuals who have employed the approach in resolving their disputes. The instruments of interview guide, focused-group discussion guide, and observation check lists were deployed to gather data for the respondents. It emerged from the study that the Nabdam indigenous conflict resolution approach is a well-structured one with four stages which has no formal place the involvement of women. It also emerged that despite modernization and proliferation of religions in the area, the approach has potential into the future due to many factors. Even though women have no official role in the application of the Nabdam indigenous conflict resolution approach, they were found to be effective in managing disputes especially those involving women. It was therefore concluded that it is due time that women should be formally involved in the application of the approach.
\end{abstract}

Keywords: conflict resolution; indigenous; peace-building; approach; custom; tradition

\section{Introduction}

Conflicts are inevitable in human life. Many African societies are faced with different forms of conflict, including ethnic, land, chieftaincy, marital and inter-personal conflicts. Practically, a huge portion of the populations in most African countries have no means of getting to urban cities to access statutory courts to resolve their conflicts. Even if they can get to the cities, few are able to afford financial expenses for legal services much needed to access the formal justice system.

But conflicts must be resolved in order to prevent them from escalating into violent actions or distractions and thereby ensure the peaceful, harmonious and stable existence of the society. To this end, apart from the formal government courts, different societies have developed and used different customary mechanisms to resolve conflicts based on their traditions and customs.

In Ghana like in many African societies, customary conflict resolution mechanisms have been developed and employed for a very long time. Again, in Ghana like other African states, formal government courts have been shaped along western model and, therefore, alien to African societies. Due to this, only small numbers of conflicts are taken to and dealt with by formal 
government structures (Akinola \& Ndawonde, 2016). Hence, the customary conflict resolution mechanisms in Africa have played and still play a significant role in resolving conflicts of various degree and thereby maintain the peace of the society.

Different ethnic groups in Ghana have established and used various customary institutions of conflict resolution mechanisms which are unique to their own culture (Gebre, Fekade \& Assefa, 2018). Studies into traditional ways of conflict resolution in the country have identified that family heads, chiefs, council of elders, and religious leaders/institutions are employing Mediation, Negotiation and Arbitration to deal with conflict (Mensah-Bonsu, 2012). These traditional mechanisms are not only used to deal with conflict among themselves but also with other people living in the country.

Among the Nabdam of Ghana, the use of chiefs and their councils of elders to resolve conflicts is very prominent. Like other African traditional conflict resolution models, the Nabdam indigenous approach (i.e. using chiefs with councils of elders) is a well- structured system which focuses on reconciliation, maintenance, restoration and improvement of social relationships of disputants (Naude, 2010). The strength of the approach lies in its deep rootedness in the people's culture and also the peoples' understanding that it often restores balance (Opasina, 2016). It is also believed to be influenced by the gods/ancestors of the land ad as well noted for providing a cheap and unintimidating environment to disputing parties for processing their conflicts (Marfo, 2014).

The legitimacy of the Nabdam conflict resolution is not only sourced to its credibility among the communities that practice it, but also to the Republican Constitution of Ghana, 1992 which guarantees the institution of chieftaincy, together with its traditional councils as established by customary law and usage (Article 270), and the Chieftaincy Act, 2008 (Act 759) that empowers the chief with his elders to arbitrate on disputes (Section 30). At the same time, in the Nabdam area of Ghana, there are a few, poorly resourced, and expensive law courts for justice delivery, which have a reputation of "justice-buying", power influence, and manipulations (Oquaye, 2013). This reinforces or strengthens the relevance of the traditional approach to resolving conflicts in the Nabdam area.

\section{Statement of the problem}

Due to limited resources, individual differences and preferences as well as aspirations, human beings are often in conflict. Conflicts threaten and affect the needed peace in society. The resolution of conflicts is therefore paramount. The process of resolving conflicts is highly crucial for effective outcomes. This is because when persons under conflict resolution processes feel their dignity and rights are compromised, that feeling has a very high potential for affecting the outcomes.

Like any modern society, the state-owned court system in the Nabdam area is manned by professionals who are trained, employed and paid by the state to resolve conflicts of people using the law. Few people in the Nabdam area employ the courts to resolve their conflicts which I presume is due to geographical and financial inaccessibility as well as the fear of "justice-buying", power influence, and manipulations (Zuure, 2020). The traditional approach (i.e. using chiefs with their councils of elders) to conflict resolution is widely used in the area.

With modernization and religious proliferation and also following persistent criticisms (by especially the Charismatic, Protestants and Pentecostalists) against traditional practices in the Nabdam area, one would have expected that the traditional socio-cultural chieftaincy institution would demise in power, authority and functions. One would also think that the institution would lose its appreciation by the people and as a result, people would resort to the court system to resolve their conflicts. To the contrary, that is not the case. Majority of the Nabdam people still employ the chiefs with their councils of elders to manage their disputes (Zuure, 2018). However, there is little scholarly knowledge on how the Nabdam traditional approach (using chiefs and councils of elders) effectively resolve disputes for peacebuilding. There is also little scholarly knowledge on structural and procedural aspects of the model. Again, little is known about the 
prospect of the traditional approach to conflict resolution in an era of modernization. This work, therefore, provides empirical or researched information on the Nabdam traditional approach to conflict resolution and its usage in the resolution of conflicts and peacebuilding. It achieved this by examining the structural and procedural aspects of the Nabdam indigenous conflict resolution and peacebuilding approach as well as the role played by women.

\section{Theoretical basis for indigenous conflict resolution in Africa}

Most African societies, if not all, lived communally and were organized along clan, village, tribal and ethnic lines before colonialism. One's belonging to a community was of great relevance, if not downright necessary. Values, norms and beliefs in the society and the threat of excommunication from the society provided chiefs and elders with legitimacy and empowered them to sanction through which they ensured their decisions were complied with. Subsequently, social theories have been developed that try to explain why chiefs and elders were able to resolve disputes in such contexts. The Social Capital, Social Solidarity, and Optimal Psychology theories underpinned this study.

\section{(a) The Social Capital Theory}

The social capital theory provides explanation to the communal nature of societies especially in Africa and the subsequent social bonds or ties that facilitates the co-existence of people. Putnam and Alone, in theorizing social capital, posits that social networks, bonds, reciprocal duties and trust, bind people together and enable them to coexist (Putnam \& Alone, 2000). These social ties have secured the existence and effective functioning of the society over time. Putnam and Alone catalogued two types of social capital: bonding social capital that fastens ties of individual members of a group; and bridging social capital that allows inter linkages with other social groups (Putnam $\&$ Alone, 2000). The social capital theory is, hence, effective in explaining the restorative nature of dispute resolution by chiefs and elders in African societies. In most of Africa, chiefs and elders mainly aim at restoring the social ties or social capital that had been broken by the wrong doing.

The theory explains that without strong social ties, members in communities would not be able to exist and function effectively. Social capital theory explains that for fear of threat of excommunication from the society, and therefore exclusion from social ties, people refrain from engaging in wrong doing.

\section{(b) Social Solidarity Theory}

Durkheim (1933) provides explanation of society relative to social order and social facts in his book entitled the Division of Labour. According to Durkheim, individuals who are society are social actors are restrained by social facts to stay and fit in society. Social facts exist only if the society can derive benefits from them. Relating this theory to dispute resolution especially by chiefs and elders, the act is seen as a social fact from which society derives some benefit. Chiefs and elders resolve disputes due to their long experience, wisdom and the respect they are accorded in society.

The social solidarity theory, being a functionalist theory, explains the resilience of dispute resolution by chiefs and elders even in modern societies that have embraced western legal systems as is the case in the Nabdam area of Ghana. Where a community cannot access formal justice systems due to costs and other externalities, chiefs and elders resolve disputes when they occur. They do this in accordance of the culture and tradition of the people Therefore, the existence of chiefs and elders is a social fact in the society providing a dispute resolution utility occasioned by the absence or low penetration of western legal systems.

\section{(c) Optimal psychology theory}

Optimal psychology theory provides explanation to how people view reality, live and resolve disputes (Myers, 1992). The theory uses culture to explain this phenomenon of human life. The 
theory, therefore, holds that optimal psychology is applied when people use their cultures to resolve disputes. This implies that dispute resolution as well as other real life conditions are suboptimal when done in line with a foreign culture. Foreign imposed justice systems such as courts are thus sub-optimal in the African context due to varying cultural context. For instance, while African traditional societies to a large extent are grouped communally, western societies are individualistic. This results in a cultural-conflict if western ideals are applied in dispute resolution. Moreover, while dispute resolution in African societies is aimed at repairing social ties and restoring harmony; foreign imposed justice systems are mainly retributive with a winner-loser ideology. This theory is important in understanding the resilience of traditional dispute resolution in modernized and westernized African societies.

\section{The indigenous concept of conflict resolution}

Indigenous conflict resolution in African societies exists at different levels right from the family through to the clan and to the community levels. These approaches mainly involve using indigenous institutions, knowledge, and ideas to deal with conflicts. Also referred to as traditional conflict resolution mechanism, indigenous conflict resolution mechanism is defined as the "capability of social norms and customs to hold members of a group together by effectively setting and facilitating the terms of their relationship... sustainability facilitates collective action for achieving mutually beneficial ends" (Fred-Mensah, 2005:35). It is a process through which stakeholders take conscious effort to work towards the management of a conflict. The main focus of indigenous conflict resolution mechanism in Africa is on re-establishing the flow of harmonious relationship within individuals, families and communities. Traditional conflict resolution is reconciliatory in nature which is often characterized with symbolic gestures and associated rituals including the exchange of gifts, and slaughtering of animals such as chickens, goats, sheep, and cows (Ige, 2015) indicates that traditional conflict resolution focuses on creating and restoring the impaired relationship with God, the spirits, ancestors, family and neighbours as the case might be.

Brock-Utne (2006) espouses that conflicts must be understood in their social context, involving "values and beliefs, fears and suspicions, interests and needs, attitudes and actions, relationships and networks...". It is therefore essential to deal with the root causes of conflicts so as to enable shared understandings of the past and present. The focus of conflict resolution especially from the indigenous perspective is as noted by Brock-Utne (2006), "to mend the broken or damaged relationship, rectify wrongs, and restore justice". Another aim is to ensure the full integration of parties into their societies again and to adopt the mood of co-operation. As aptly put by Brock-Utne (2006), the overall objective of traditional conflict resolution is to avoid accusations and counter-accusations, settle hurt feelings, and reach a compromise with a greater focus on helping improve the future relationship of the parties involved.

The key players in traditional conflicts resolution depend on the level at which it is being handled. Some conflicts can be processed at the family level with family heads or at the community level with the chief and elders. The roles played by the key actors does vary from time to time as demanded by situations. This is due to the absence of standard model with indigenous conflicts resolution processes. Thus, the traditional conflicts resolution approach is flexible and dynamic and the whole process and content are influenced by the social context.

Generally, traditional conflict resolution involves the identification of the root cause of the problem and engaging all parties concerned to address the underlying issues. This usually ends with the guilty party(ies) acknowledging and accepting wrongdoing, which potentially leads to reconciliation. Usually, the process ends with either a compensation or just forgiveness (Akinola \& Uzodike, 2017). The process of traditional conflict resolution uses culture and indigenous structures as well as systems to ensure peace at various levels of relationship. In this respect, conflict resolution procedures are generated from general cultural life and daily experiences of living. 


\section{Traditional conflicts resolution in Ghana}

Traditional leaders take up vital role in the structured conflict resolution process in Ghana. This is done to ensure socio-economic development and the administration of justice even in contemporary times (Zuure, 2018). This forms part of the cultural heritage of the people of Ghana where traditional leadership performs important roles towards social cohesion, peace and order in societies.

There are many persons involved in the traditional conflict resolution process in Ghana. These persons include family and clan heads, chiefs with their elders and queens. Sometimes, some actors are drawn from sections of society including clans, youth, women, singing and self-help groups/associations. In some societies, the traditional priests are significant actors in the resolution of conflicts. This study focused on chiefs and elders. Traditional conflict resolution mechanisms in Ghana mostly employ open-discussion aand consensus building. The main and regular actors in conflict resolution in Ghana are persons within the traditional authority structure. The composition of the traditional authority also demonstrates the Ghanaian traditional notion of participatory democracy (Zuure, 2018). The traditional process of conflict resolution in Ghana especially the Nabdam is based on the notion that whatever decision is arrived at should improve the relationship between the parties and that the judgment should be wise and practical (Zuure, 2018).

The setting or venue for traditional resolution of conflicts is very crucial. A neutral ground is often selected for traditional conflict processing event due to the value of conciliation embedded in the traditional approach (Esia-Donkoh, 2012). This informs why cases are often processed at the chief's palace (Best, 2006; Kirby, 2006). When land boundary is the basis for the conflict, then the boundary in contention could be used as the venue. Under such instances, the earth goddess, as well as the ancestors, are invoked as they are regarded as the real owners of land (Best, 2006).

Esia-Donkoh (2012) contends that there are cultural and spiritual connotations to the choice of neutral grounds for the traditional processing of conflicts. It shows that the communal interest of the people is supreme, hence, the interest of the community must be placed above individuals' interest. Also, the choice of a neutral grounds indicates there is a dependence on the spirit beings to witness and assist in the resolution process so as to achieve harmony. Thirdly, the choice of some neutral grounds like the palace and shrine symbolizes the support and heritage of the entire community (Esia-Donkoh, 2012). Generally, a traditional conflict resolution process has three stages which include the pre-resolution, resolution, and post resolution (Manuh, 1988; EsiaDonkoh, 2012).

The traditional conflicts resolution process in Ghana involves the use of social, spiritual, and material tools (Awedoba, 2015; Kendie, 2010). The spiritual tools involve the performance of rituals such as sacrifices, libation, incantations, and prayers supposed to engage the ancestors in the disputing process. The social tools include the use of proverbs, marriage ties, historical experiences, joke relationships etc. Some of the material tools used included the use of local foods, drinks, and fines.

\section{Methods of traditional conflicts resolution}

Various methods are applied in traditional conflict resolution. Some of these methods include mediation, arbitration, negotiation, and conciliation. The methods each have a definite practice, procedure and time.

Negotiation according to Horowitz (2007), is a process where two or more parties in conflict open a dialogue and use offers and counter-offers in an effort to build a mutually acceptable agreement. For American Bar Association (ABA), 2006, negotiation can also be a process of communication whereby the representatives of conflicting parties seek to resolve their conflicts and work to bring a mutual agreement for the parties. With this method, the parties to a conflict are made to engage each towards the resolution of their conflicts. Parties share their concerns regarding the conflicts and they work out a settlement agreement satisfactory to them. The 
traditional leader employing this method admonishes the parties to listen to each other, appreciate the feeling and hurts of each other, and then fashion out satisfactory agreement to resolve the conflict. After parties have reached an agreement, they report to the traditional leader who takes them through feasting activities such as sharing drinks, food, or even a handshake.

Mediation is a consensual conflict resolution method in which an independent neutral third party intervene in order to facilitate negotiation and assist the parties in conflict to resolve their conflict and reach a mutually acceptable agreement (ABA, 2006). In the process of mediation, the mediator must be accepted by all parties. He/she does not have decision making power about the conflict. Rather the task of a mediator, according to Moore (1986), is creating the conditions for an open dialogue. It also includes; assuring the parties involved in the conflict freedom of speech, clarifying issues, identifying and managing emotions, and creating options, thus making it possible to reach an agreement (Horowitz, 2007). Therefore, some researchers argue for mediation as it helps the parties in conflict to arrive at an agreement. For instance, Fisher and Ury (1981), speak of joint problem solving to reach a win-win solution. This method also has a good potential to restore relationship which is central to the traditional conflicts' resolution process.

However, different writers criticize the role of mediation in bringing mutually acceptable agreement, thus, categorize mediation into less directive and directive mediation (Horowitz, 2007), or pure mediation and mediation with power (Ramsbotham, Woodhouse, \& Mial, 2015). Horowitz (2007), contends that, with the less directive mediation, the mediator facilitates the flow of dialogue. The mediator in the more directive one is very concerned with the result of the mediation, thus provides personal opinions and even offers guidance on the content of the agreement. Ramsbotham et. al (2015), argues that in pure mediation, the conflicting parties maintain control over the outcome, but the process can sometimes be combined with positive and negative incentives in the case of mediation with power.

Reconciliation is another method of conflict resolution which is close in meaning to pure mediation. In this process, conflicting parties assisted by a neutral conciliator (in this case the traditional leader), identify the issues, explore options and attempt an agreement (Ramsbotham et. al, 2015). Reconciliation is the restoration of a state of peace to the relationship, where the parties are at least not harming each other and can begin to be trusted not to do so in future. Reconciliation, in this case, is a situation in which revenge is foregone as an option and conflicting parties come back together to work harmoniously together. Central to reconciliation is forgiveness in which the moral debt is cancelled, anger and resentment are dropped and thus, there will be no revenge (Webel and Galtung, 2007).

Arbitration, according to ABA (2006), is a process for obtaining a ruling of judicial character without going before a court. In this process, the arbitrator has decision-making power to resolve a conflict after considering the representations of the parties (Tsongo, 2012). The elected but unpaid judges (in the case of this study, the chiefs and councils of elders) decide cases without written law, resolving the conflict by minimizing the sense of injustice and outrage felt by the parties of a case.

There is no defined method for specified kinds of conflicts, hence, a combination of the methods can be done towards processing a conflict at hand. Actors or practitioners, directed by the will of parties in conflict and the conflict situation, must decide whether it is best to engage in negotiation and/or mediation, to offer arbitration and/or conciliation, etc. (Tsongo, 2012).

\section{Method}

This part outlines the methodology deployed in the study.

\section{Participants}

A sample of thirty (30) persons consisting five (5) chiefs, ten (10) elders, and fifteen (15) disputants who had come before chiefs for settlement of their disputes were involved in the study. These people were considered to be well placed to provide right and relevant responses or answers 
to my interview questions since the chiefs and elders were the people who manned the application of the traditional approach to conflicts resolution in the area, and the disputants had personal experiences when it came to employing the approach to resolve conflicts.

The Nabdam District in the Upper East Region was handpicked for the study partly because of the widespread use of the indigenous approach to resolve conflicts in the area and also due to the almost non-existing literature on the use of the approach to conflict resolution and peacebuilding. The sample population of 30 was drawn from five traditional areas within the Nabdam District namely Kongo, Nangodi, Sekoti, Zanlerigu and Peligu. The five chiefs and ten elders were selected through convenience sampling method. I depended on the chiefs and elders to refer me to the 15 people in the community who had used the approach to resolve their disputants. I traced to the houses of these persons and fortunately, all the disputants I approached obliged or accepted to be part of the study.

\section{Design}

The current study was designed to examine the indigenous conflict resolution and peacebuilding among the Nabdam of Ghana. aThe descriptive study design of qualitative research paradigm was used for this study. This design was appropriate in presenting accurate picture of the specific details of the Nabdam indigenous conflict resolution mechanism and peacebuilding. Again, the design was effective in the asking the "how" and "who" questions of the approach (Neuman, 2007). As a result, I was able to present the accurate detailed description of the phenomenon of Nabdam conflict resolution and peacebuilding.

\section{Materials}

Semi-structured interview, focused-group discussion, and observation were employed for the collection of data for the study. All the chiefs, five elders, and fifteen disputants were engaged in one-on-one face-to-face interview on the structural and procedural aspects of the approach, role of women in the use of the approach, and the prospects of the approach into the future. The other five elders (one each from a palace) were engaged in a focused group discussion the procedural aspects of the approach, roles of women in the use of the approach, and the prospects of the approach into the future. I also observed three live processing of cases at three chief palaces. The use of these instruments allowed for the triangulation of the results. These allowed for the collaboration or rejection of the data gathered.

\section{Procedure}

Semi-structured interview guide was used to gather data from the respondents. Each participant decided on the date, time and venue to meet for the interview sessions. At the meeting with each of them, they were told the focus of the study was to explore the indigenous conflict resolution ad peace-building mechanism among the Nabdam which they were identified as persons with significant information to enhance the study. They were told the information was taken from them for purely academic purpose. Subsequently, they were admonished to be frank with their responses.

The questions were asked to them one after the other. They were given enough time to think through the questions before providing responses. The questions were open-ended, hence, follow-up questions were asked for clarifications and details in responses. The responses were captured with a recording device. Permission was sought from them before the recording of their responses. I also took notes in my jotter. This was to enable me make reference to what the interviewees have said in later time. They were assured that their responses would be treated anonymously. At the same time, they were told they could withdraw from the interview at any time they felt uncomfortable and unwilling to continue. All persons sampled for the study agreed and were part of the interview sessions from the start to end. When the interview sessions were over, interviewees were thanked for their time, ideas, and information provided for the study. 
Interview data were later transcribed in detail. This was followed by content analysis. This was done along themes that were derived from the research objectives. As a result, responses to questions on the various themes were analysed under their respective themes. Convergent and divergent responses to questions under the various themes were highlighted and analysed.

\section{Results and discussion}

This section presents the findings obtained and discussions. It covers the structural and procedural aspects of the approach, the role of women with the approach, and the prospect of the approach into the future in line with the research objectives and questions.

\section{The structural and procedural aspects of the Nabdam indigenous conflict resolution and peacebuilding}

The first research question was set to elicit information on the structural and procedural aspects of the Nabdam indigenous approach to conflicts resolution and peacebuilding from the chiefs, elders and the disputants who have had experience of the approach. The structural and procedural aspects of the approach was deemed very important since, in many instances/events, the process is as important as the end result. This is also because many scholars have indicated that African indigenous conflict resolution approaches are well-structured and time-proven social systems (Naude, 2010). Again, in the formal judiciary system, the substantive aspect is distinguished from the procedural aspect of the law. Mondak (1991) writes that substantive law refers to the body of rules that determine the rights and obligations of individuals and collective bodies while the procedural law is the body of legal rules that govern the process for determining the rights of parties. To this end, a number of sub-themes were developed to ascertain this.

\section{Initiating a case in the Nabdam chief's palace}

This section sought to understand how anyone who needs to have his or her case reported at the palace for settlement goes about it. All the chiefs gave a similar procedure though some had slight differences. The chiefs were asked to take me through how a case is reported at their palaces.

An Elder gave the following response:

A case cannot be reported directly to me the chief, and so, is first reported to an elder. The elder then comes to inform me in private about the request of the person. After the elder reports the case to me, I will ask the elder to come with the complainant to the palace for the case to be reported to the chief officially. When the elder and the complainant appear at the palace, the complainant is given the opportunity to make a report of his or her case with either an amount of money or animal or a combination as a filing fee.

Another Divisional Chief also said:

Anyone desiring for his or her case to be processed at the palace has to first report the case to any of my elders. The said elder will determine whether the case merits to be heard in court or not. If the elder decides that the case should not get to the chief, the rest of the other elders are called in to handle it without the involvement of the chief. If the case must get to the chief, the elder makes a formal report to the chief on behalf of the complainant. The chief then asks the elder to come with the complainant to register the case. The complaint registers his or her case at the palace with a filing fee which could be an amount of money or animal(s). It is the complainant who decides on how much or what animal(s) or even a combination to file a case with. 
A Paramount Chief on his part said: Cases for processing at the Paramount Chief's level are referred from Divisional Chiefs. Even if an aggrieved person comes to me first, I will refer him or her back to the Divisional chief. So cases that Divisional Chiefs are unable to handle are referred here. The Divisional Chief involved brings the disputants. The Divisional Chief concerned comes with the disputants, greets and indicates whether he was unable to resolve the case satisfactorily or he considered the case beyond his capacity. The filing fee at the Divisional Chief's level is brought to register the case here.

It can be seen that, with the Nabdam indigenous conflicts resolution process, no one goes directly to the chief to report a case for processing. According to a Divisional Chief in an interview session, this was put in place by the forefathers to show respect to the chief. The good thing is that the person desiring his or her case to be heard has a number of elders at his or his convenience to approach and start the process of reporting the case. I support the practice of allowing cases to be reported to any of the elders because that will enhance quick access to reporting, hearing and resolution of cases since the elders stay in various part of the communities. I also contend that the thinking behind not allowing persons to report their cases directly to the chief is very appropriate as that practically shows respect to the authority of the chief and hence, places him in the capacity to deal with issues in a manner that will ensure peace and harmony.

Cases get to the Paramount Chief's palace for resolution through a referral from a Divisional Chief. A Paramount Chief insisted that all cases for consideration at the Paramount Chiefs place must be brought from the palace of a Divisional Chief, else, he refers the disputants back to the Divisional Chief. The insistence that cases to the Paramount Chief's palace must go through Divisional Chiefs is important in ensuring structures of authority are followed and that the Divisional Chiefs are not undermined.

Generally, cases are reported to any of the elders in the palace to be forwarded to the chief. Sometimes, the elder can decide whether the case should get to the chief or not. On a decision not to let a case get to the chief, the elders by themselves can settle the case. This is similar to the Akans' as noted by Manuh (1988) that the elder who receives the case from the complainant determines the merit of the case to be heard by the chief. The complainant determines the filing fee which has traditionally been animal(s) but in modern times can be money. There is, therefore, no imposition and this takes away financial inaccessibility to justice from the process. This also makes people to be so certain or sure that they have cases before they appear at the chief's palace to make reports since losers forfeit whatever they used to file their case.

The structured nature of initiating a case at the palace of a chief in the Nabdam area serves to limit the numbers of cases to be reported there. This was made clear at a Focused-Group Discussion with elders where they explained that the structured nature of reporting a case at the palace was meant to make people intending to initiate a case get to meet and interact with respected persons whose words of advice and actions can provide comfort and reduce if not take away the pains in them and subsequently reduce the possibility of going through the process.

The process of initiating a case in the traditional courts in the Nabdam area is similar to the account by Manuh (1988) of the Akan. The slight difference is the elders having the power not to admit cases they did not consider good enough to reach the chief in the case of the Akan. With the Nabdam, any case considered not good enough to be heard by the chief is handled by the elders but not refused total admission.

\section{Hearing a case in the chief's palace in the Nabdam area}

Next was on how hearing of cases was conducted after the cases were duly reported. The process through which the case is heard is very important to the acceptance of the outcome by the disputants. This is especially crucial with the Nabdam indigenous approach since its overarching focus is to maintain relationships and foster social harmony. The responses from all the chiefs to 
this all-important aspect of the process depicted a similar pattern. For example, a Divisional Chief explained how a hearing on cases was done in his palace as follows:

On the day of the hearing, when the chief with his elders is seated, each of the disputants takes turns to greet the chief and announce their presence with kola as kola is the traditionally required item to greet a chief in the Nabdam area. After the greeting, everyone is reminded of the presence of the gods and ancestors of the land to witness and take part in the process. By this, everyone is called to be honest and truthful. Therefore, people often speak the truth for fear of being dealt with by the gods and ancestors if they told lies. Everybody fears the spirits. After the chief has reminded every one of the presence of the gods and ancestors, the elder who received the case and reported to the chief is asked to call the case for consideration. When he is through calling the case, the complainant is usually called upon first to take a seat on the floor and present his or her complaint. He or she has all the time required to give an adequate presentation of the case and as he or she is making the presentation, no one interrupts him or her; everyone listens attentively. If he or she bas evidence to support his or her case, he or she is expected to use them during the presentation in a manner that will help make his or her side of the story better. After the presentation by the complainant, the defendant takes his or her turn to sit on the floor and present his or her side of the case. Similarly, no one interrupts and the defendant also bas all the time required to adequately present his or her case. If the defendant also has evidence, he or she is expected to present them during his or her presentation in a manner that will help him or her.

A Disputant on his part narrated how hearings are conducted as follows:

On the date of hearing, the disputants with or without people accompanying them appear. After normal greeting exchanges, we get down to the case. The complainant is first given the opportunity to state his or her case. He is free to express himself or herself in the manner he or she feels comfortable in. As the complainant makes a presentation, all persons are to listen calmly. When the complainant is done, the defendant is given the floor to present his or her side of the case as everyone listens.

The explanations given above show the indigenous approach has a pattern it follows in hearing cases. My observations of three live disputes processing in three palaces corroborate the descriptions of how cases are heard with the Nabdam approach as presented by the chiefs captured above. My observation saw the elder in charge of the palace "kpaana" would always call the traditional court to order and ask the elder who led the complainant to report the case to call the case for hearing. The approach satisfies the law of natural justice which requires every person accused be given a fair hearing before judgment is passed. This finding makes the Nabdam traditional conflicts resolution approach a potential means to ensuring peacebuilding. The manner in which cases are heard with the Nabdam approach to conflicts resolution is akin to the accounts of the Akan's given by Manuh (1988) and Esia-Donkoh (2012); and Ewe's by Togbe Satsi III (2017).

\section{Concluding on a case in a Nabdam traditional court}

When the panel of chiefs and elders of the traditional court sit and take the disputants through the process of hearing the case, allowing for cross-examinations and appearance of witnesses, the next thing as expected is that the case is brought to a close. One important thing with the Nabdam traditional conflicts resolution process is that most of the time, the disputants usually get to concede fault when they are taken through the process. The focus of the approach is conciliation; hence, the approach usually engages the disputant to get a result that will foster cordial relationship among disputants after the process. Nonetheless, there are instances where none of the disputants accepts fault after they have been taken through the process. When that happens, the elders share their just and honest opinions to reach conclusions on cases. One Divisional Chief indicated how cases are concluded as follows: 
At the end of the presentations by the complainant and defendant, cross-examination, presentations by witness(es), questions by the elders and chief, the disputants always get to know who is right and who is wrong. The disputants would usually ask for an excuse to go and meet with the people who accompanied them to the palace and take decisions. Upon return, one of the parties is expected to concede and it usually does happen. In the event that none of the disputants accepts to be at fault, the elders' views (without the chief) are taken in private and the decision announced by the linguist. The chief is not part of taking the final decision so as to isolate bim from being seen as bias, especially by the losing party and associates. This way the chief remains neutral. In few instances, however, the opinion of the chief is sort but in a tactical manner.

A Paramount Chief in a similar version espoused the following:

At the end of the presentations and questioning, the disputing parties with their respective family members and friends move out for some time to confer and take decisions on what has transpired. When they return, the accused is expected to accept guilt or eject the case made against him or her. If the accused accepts fault, that becomes the end of the case but if he or she does not accept fault, the complainant is required to say whether after what has been said, he or she still thinks he or she has been wronged. If neither the defendant nor the complainant concedes fault, the elders move into private to express their views on the case and a decision is taken. In some instances when the disputants do not concede fault, the case is adjourned to another date for them to sleep over it, think and reflect on it, and also seek wisdom from the gods and ancestors so as to be able to deliver just judgment.

From the above, it can be seen that the process is opened and plain and often produces fair results as disputants often get to understand the aspects of their cases better and proceed to conclude their cases by themselves. This certainly ensures harmony and cordial relationship among disputants after the settlement process. By this, the process can be described as mediation where the chiefs and elders act as neutral third parties to assist the disputants to resolve their disputes.

The practice of disputants conceding after the hearing indicates that the process is well structured to bring out the truth. This is a positive thing about the Nabdam indigenous approach to conflicts resolution. This also makes the Nabdam indigenous approach unique as I have not read or heard about a similar thing from anywhere. The Nabdam indigenous approach is different from the accounts of Manuh (1986) and Esia-Donkor (2013) who indicate that among the Akan of Ghana, it is the elders who take the decision of who is wrong and who is right; and Togbe Satsi III (2017) who indicates, it is the chief and elders who take the decision among the Ewe.

\section{Sanctions with the Nabdam indigenous conflict resolution approach}

Sanctions with traditional approaches are not meant to punish since the focus of these approaches is to maintain a harmonious relationship between parties. Sanctions are therefore meant to appease victims. The principal sanction to the party at fault with the Nabdam indigenous approach to conflicts resolution is the forfeiture of the filing fee. Additional charges in the forms of a fine of money or animal(s) can be imposed on the guilty party depending on the gravity of the offence. One Divisional Chief offered the following response to the question on the forms of sanctions delivered by chiefs and elders with the Nabdam indigenous approach:

I don't know if we should call it sanction. What happens is that the guilty person forfeits his or her filing fee which is either money or animal(s) or both, whiles the winner takes his or her's back. In some cases, however, the chief can issue additional sanctions such as a fine of money, fowl, goat, cow, or a combination. This will only happen if the magnitude of the case is grave. The sanction is to serve as deterrence to the guilty person and other people so that they would relate well with others in society. Where an additional charge is given in addition to the filing fee, the loser can in private go to the chief to negotiate for reduction. No torturous and humiliating actions such as beating are given. As a chief, I am a father to everyone and must care for all. If I allow for such 
things, others will certainly abuse it which can lead to harm or death and I will be held responsible. Therefore, our sanctions end with the filing fee, fine of money, animal(s) or a combination.

An elder corroborated the view expressed by the Divisional Chief as follows:

When a case is brought here and a determination of who is at fault is made, the guilty party forfeits his or her filing fee. This is to deter them and other people from misbehaving in the future and also to comfort the victor. There may also be a fine of money depending on the nature of the case.

The sanctions with the Nabdam indigenous approach to conflicts resolution serve to check on people deciding to report cases to the traditional courts for processing. As indicated earlier, filing a case comes with a filing fee in the forms of animal(s), money or both and if losing a case would result in the forfeiture of these items you have used to file, people will critically analyse issues before reporting them at the palace.

One important thing about the sanctions with the Nabdam indigenous approach is the winner does not take any part of the loser's forfeited things away. It is used to refresh the panel who sat on the case, and for the royal service. The sanction system employed by the Nabdam indigenous approach promotes peacebuilding.

\section{The role of women in the Nabdam indigenous conflict resolution and peacebuilding}

This part examined the role of main actors with the Nabdam indigenous conflict resolution with a view to understanding the role of women in the application of the approach. Generally, conflict resolution involves recognizing the root causes of the problem and working the parties involved to to find solutions to the underlying issues. This requires the people to make this happen to be technically proficient and generally accepted, hence, the actors in the conflicts' resolution process is very significant. The chiefs and elders indicated that the actors are those along the traditional authority structure in the area. The Nabdam traditional authority structure stretches from the family head, through clan head, sub-divisional chief, divisional chief to the paramount chief.

It emerged from the study that women have no official role in the application of the indigenous mechanism in the area. Only chiefs with their elders (all male) are the main persons involved in resolving conflicts using the indigenous approach. They pointed out that all the chiefs have some regular elders with whom they worked. These elders as mentioned by a Divisional Chief included: "Kanbongnaab" (responsible for external relations), "Kpanna" (in charge of the palace), "Bihenaab" (in charge of the youth), Äduu" (linguist), and "Yidaan" (usually the eldest son of the chief). The following captures his view:

I don't sit on cases alone, no way!!! I have elders - kpanna, kanbongnaab, aduu, bihenaab, and yidaan that I usually invite to sit in court to handle cases. These are my able men with great wisdom who make things happen here with most of the people if not all who come here leave satisfied.

This attribute of chiefs and elders serving as major actors in indigenous conflicts resolution in the Nabdam area is similar to the practice in other parts of Ghana and Africa as contains in works on African traditional conflicts resolution (eg. Marfo, (2014). Again, it corroborates Nwosile (2005) when he wrote that the actors in African traditional conflicts resolution are elders, clan chiefs, prominent leaders, acceptable and respected persons (eg. great hunters).

However, unlike the Akan where all levels of traditional authority have corresponding female actors (Manuh, 1988; Esia-Donkoh, 2012), and the Ewe of Volta Region (Togbe Satsi III, 2017), the Nabdam traditional structure has no such role for a female. When the chiefs were asked about the role of women in traditional conflicts resolution in the area, all the five chiefs responded that women have no role to play in the process. The structure of the Nabdam 
traditional authority without women is akin to the traditional authority of the Ga in the Greater Accra Region. The chiefs, however, indicated that in recent times, following calls from the National House of Chiefs, they are trying to work with women leaders in the communities known as "mangaazien". The "mangaazien" are not queen; they are just women who lead in the organization of other women in the communities due to their own leadership attributes, hence, they hold no traditional authority. Notwithstanding, one Divisional Chief had this to say about the role and involvement of women in traditional conflicts resolution process in the area:

Even though women traditionally have no place in traditional authority and in resolving conflicts, I have been working with the "magaazien" especially on cases that involve women. I recognise that women are the source of nature, full of wisdom and ideas. I equally recognise that even we men came from women and so women are very important. I, therefore, have been inviting the "mangaazie" to come and sit in to process some cases. I also sometimes, refer women to her to assist them to resolve their cases after which she reports back to me.

The absence of an official role for women in the conflicts' resolution process in the Nabdam area may be attributed to the patriarchal nature of the society. Patriarchy, broadly refers to the institutionalization of male dominance over women and children in society (Jagger \& Rosenberg, 1984). This implies that men control resources and institutions of society which results women been deprived of access to such resources and institutions.

Summarily, the main actors in the Nabdam disputes resolution include the chiefs and their councils of elders. This finding of males as the major actors with the Nabdam traditional conflict resolution process corroborates the view of Elechi (2004) when he wrote that adult males dominate the process of conflict resolution in Africa.

\section{Conclusion}

The Nabdam indigenous approach to conflict resolution and peacebuilding has served to a large extent in managing conflicts in the area. Judging from the findings discussed above, it can be conveniently concluded that the Nabdam indigenous approach to conflict resolution and peacebuilding is a well-structured, flexible, and efficient mechanism that employs restorative and transformative principles in conflict resolution. The approach is process-oriented, rather than rulebased. Its emphasis is on the processes of achieving peaceful resolutions of disputes rather than on adherence to rules as the basis of determining disputes. The approach can be categorized into four stages namely; the initiation, processing, concluding, and consolidating stages. The approach is patronized largely for the resolution of conflict which accounts for the relatively peaceful nature of the Nabdam area.

The indigenous approach to conflict resolution reveals the patriarchy nature of the Nabdam area. Women are identified with the capacity to resolve conflict and build peace in the Nabdam area and have been used informally in the processing of conflicts especially those conflicts involving women. Notwithstanding, women have been left out in the formal traditional authority structure, hence, no formal role in conflict resolution and peacebuilding in the area. The absence of women in formal capacities in resolving conflict and building peace tend to reduce women to people who are unable to be creative to deal with issues and derive successful outcomes. This does not only discriminate against women in the area, but deprives people especially women of fantastic feminine perspective to conflict resolution and peacebuilding in the area.

Finally, the people of Nabdam are conservative especially to their traditions, customs, and culture. Notwithstanding the pervasive influence of modern religion and modernization, the people in the Nabdam area are still very much held to their custom-based approach to conflict resolution and peacebuilding. Together with the many advantages with the indigenous approach is seen as effective means to conflict resolution and peace-building in the area. 


\section{References}

Akinola A., \& Uzodike, (2018). Ubuntu and the quest for conflict resolution in Africa. Journal of Black Studies 2018, 49(2) 91-113.

Akinola, A. O., \& Ndawonde, N. (2016). NEPAD: Talking from the South, governing from the West. International Journal of African Renaissance Studies: Multi-, Inter- and Transdisciplinarity, 11, 38-51.

Awedoba, A. K. (2015). Living in the age of conflict: exploring the role of indigenous solutions in conflict management/resolution in Northern Ghana. In S. B. Kendie, (ed), Conflict management and peace building for poverty reduction. Tamale: Centre for Continuing Education and Interdisciplinary Research, University for Development Studies.

Best, S. (2006). The methods of conflict resolution and transformation. In Best, G.S (ed.), Introduction to Peace and Conflict Studies for West Africa (pp, 93-115). Nigeria: University for Peace.

Brock-Utne, B. (2006, February, 23-24). Indigenous conflict resolution in Africa [Paper Presentation]. Weekend seminar on Indigenous Solutions to Conflicts. University of Oslo.

Bowd, R. (2009). Access to justice in Africa: Comparisons between Sierra Leone, Tanzania and Zambia. Institute for security studies policy brief", 13, 1-5.

Chieftaincy Act 2008, Act 759. Accra: Assembly Press.

Elechi, O. O. (2004, August 8 -12). Human rights and the African indigenous justice system [Paper presentation]. 18th International Conference of the International Society for the Reform of Criminal Law. Montreal, Quebec, Canada

Esia-Donkoh, K. (2012). Traditional conflict resolution in the Ghanaian context. In Eric Sakyi Nketiah (ed), Distance Forum Vol. (2). Abossey Okai: Defalis Concept.

Fisher, R., \& Ury, W. (1981) Getting to yes. New York: Houghton Mifflin.

Fred-Mensah, B. (2005). Nugormesese: An indigenous basis of social capital in a West African community. $1 \mathrm{~K}$ Notes, No. 86. World Bank.

Gebre, Y., Fekade A., \& Assefa, F. (2018). Customary dispute resolution mechanism in Ethiopia. Addis Ababa: The Ethiopian Arbitration and Reconciliation Center.

Horowitz, S. (2007). Mediation. In Webel, C. and Galtung, J. (Eds). Handbook of Peace and Conflict Studies, pp, 51-63. London and New York: Rutledge.

Ige, R. A. (2015). Legal Pluralism in Africa: Challenges, conflicts and adaptation in a global village. Journal of Law, Policy and Globalization, 34, 68-75.

Jagger, M. A., \& Rosenberg S. P. (1984). Feminist Frameworks. New York : MC Grew-Hill.

Kendie, S. B. (2010). Conflict management and peace building for poverty reduction, a policy breief following 2010 Harmattan School. Center for Continuing education and Inter-Disciplinary Research. Tamale: University for Development Studies.

Manuh, T. (1988). The Asantehemaa's court and its jurisdiction over women: A study in legal pluralism. Research Review, 4(2), 19-24.

Marfo, S. (2014). Indigenous Ghanaian conflicts resolution and peace-building mechanism, reality or illusion: A reflection on funeral among the people of Apaah and Yonso in the Asanti Region. Online Journal of African Affairs, 3(8), 124 - 133.

Mensah-Bonsu, H. (2012). Mechanics of disputes resolution for managers of tertiary educational institutions. Accra: Adwinsa Publications (Gh) Ltd.

Myers, L. J., \& Shinn, D. H. (2010). Appreciating traditional forms of healing conflict in Africa and the world. Black Diaspora Review, 2(1), 6-12.

Naude, W. (2010) Development progress in Sub-Saharan Africa: Lessons from Botswana, Ghana, Mauritius and South Africa. Working Paper No. 2010/07. Helsinki, Finland, United Nations University and World Institute for Development Economics Research.

Neuman, W. L. (2007). Basic social research: Qualitative and quantitative approaches (2nd edition). Boston: Pearson Education, Inc.

Nwosile, O. B. (2005). Traditional models of bargaining and conflict resolution in Africa: Perspective on peace and conflict in Africa. Ibadan: John Archers Ltd.

Opasina, O. K. (2016). Traditional institutions and the challenge of modernity in Nigeria and Côte d'Ivoire. International Journal on World Peace", 33(2), 43-75. 
Oquaye, M. (2013). Democracy and conflicts resolution in Ghana. Accra: Gold-Type Publications Ltd.

Ramsbotham, O. Woodhouse, T. \& Miall, H. (2015). Contemporary conflict resolution. Cambridge: Polity Press. Republican Constitution of Ghana (1992). Accra: Assembly Press.

Togbe Satsi III (2017). Oral interview with the researcher. November, 2017.

Tsongo, C. (2012). Introduction to conflict analysis, prevention and resolution [MA Thesis in Gender and Peace Building, University for Peace].

Webel, C., \& Galtung, J. (2007). Handbook of peace and conflict studies. New York: Routledge.

Zartman, I. W. (2017). Conflict management: The long and short of it. SAIS Review, 20(1), 21-26.

Zuure, D. N. (2018). Legal pluralism, conflict resolution and human rights: examination of traditional conflict resolution among the Nabdam of Ghana $[\mathrm{PhD}$ thesis, Department of Social Studies, University of Education, Winneba].

Zuure, D. N. (2020). Indigenous conflict resolution and the protection of human rights among the Talensi of Ghana. East African Journal of Education and Social Sciences, 1(3), 1-11. 